\title{
Generalised peripheral nerve dysfunction in acromegaly: a study by conventional and novel neurophysiological techniques
}

\author{
G A JAMAL, * D J KERR, $†$ A R McLELlAN, $\dagger$ A I WEIR,* D L DAVIES $\dagger$ \\ From Glasgow University Department of Neurology, ${ }^{*}$ Institute of Neurological Sciences, Southern General \\ Hospital, and Glasgow University Department of Medicine, $\dagger$ Gardiner Institute, Western Infirmary, \\ Glasgow, UK
}

SUMMARY Twenty four patients with clinical, radiological and biochemical evidence of acromegaly were investigated by a number of independent neurophysiological tests. Two-thirds of the patients showed evidence of generalised peripheral nerve dysfunction. A significant correlation was found between total exchangeable body sodium, an indicator of disease activity, and the severity of the neuropathy. The generalised peripheral nerve abnormality was found to occur independently of the associated carbohydrate intolerance human growth hormone levels and other endocrinological dysfunction in this disorder.

The association of median nerve entrapment at the wrist with acromegaly is well known ${ }^{1-5}$ and is probably due to compression of the nerve by hypertrophic connective tissue. ${ }^{367}$ Unilateral or bilateral carpal tunnel syndrome is one of the first symptoms in $12 \%$ of patients with acromegaly ${ }^{8}$ and later in the course of the disease the incidence may rise to as high as $35-47 \% .^{89}$ Generalised neuropathy is a much less recognised complication and only occasional reports have appeared. ${ }^{10-17}$ This neuropathy was found to be predominantly sensory in nature ${ }^{18}$ but severe muscle weakness and wasting have been described. ${ }^{13}$

Although believed to be related to the disease process, no correlation has been found between this peripheral nerve dysfunction and indices of human growth hormone (HGH) secretion and the associated glucose intolerance. ${ }^{815}$ This finding was not based on statistical analysis of this correlation in an adequate number of patients but rather on observations on individual patients.

We have looked for evidence of a generalised peripheral neuropathy in 24 patients with acromegaly and have correlated our findings with measurements

Present address and address for reprint requests: Dr Goran A Jamal, Department of Neurological Sciences, St Bartholomew's Hospital, London EC1A 7BE, UK.

Received 13 May 1986 and in revised form 8 October 1986. Accepted 10 October 1986 of body composition, circulating HGH concentration, thyroid dysfunction, total exchangeable body sodium and other endocrine data. The relative frequency of involvement of large versus small fibre afferent pathways was assessed using conventional electromyography and nerve conduction studies, our recently introduced technique for the study of thermal thresholds ${ }^{19}$ and the technique of Goldberg and Lindblom $^{20}$ for the quantitative measurement of vibration thresholds.

\section{Methods and materials}

THE NEUROPHYSIOLOGICAL TECHNIQUES

Electromyography and nerve conduction studies

Electromyography (EMG) and nerve conduction (NC) studies were performed using a Medelec MS91 electromyograph. The fastest motor nerve conduction velocity (FMNCV) and the shortest distal motor latency (SDML) for the right lateral popliteal nerve (LPN) and median nerve were recorded from surface electrodes over the extensor digitorum brevis (EDB) and abductor pollicis brevis (APB) muscles respectively by conventional techniques. ${ }^{21}$ The sensory nerve action potentials (SNAPs) were elicited orthodromically in the right median and sural nerves. For each SNAP measurement, 64 potentials were averaged. Sensory latencies were measured from the onset of the stimulus artefact to the peak of the negative deflection. Amplitudes were measured from peak to peak. For median SNAP studies, the method of Gilliatt and Sears ${ }^{22}$ was followed. The sural nerve was stimulated at the lateral aspect of the foot immediately 
inferior and anterior to the lateral malleolus and the potential recorded by surface electrodes $12-14 \mathrm{~cm}$ proximal to the malleolus and lateral to the tendo achillis. The distance between the recording and the reference electrodes was $4 \mathrm{~cm}$. Electromyographic studies were performed with concentric needle electrodes in the APB and the EDB muscles. The ambient room temperature was kept at $22 \pm 2^{\circ} \mathrm{C}$. Skin temperature of the limb was maintained at $34 \pm 1^{\circ} \mathrm{C}$ using a thermostatically controlled heating lamp.

\section{Thermal thresholds measurement}

Thresholds for appreciation of heat (HT) and cold (CT) were determined for the volar aspect of the right wrist just proximal to the distal wrist crease and for the medial aspect of the right ankle behind the medial malleolus. These were expressed in temperature change from the basal skin temperature (before application of the stimulus) using a microcomputer controlled system and the two-alternative forcedchoice method of psychophysical analysis (The Glasgow Thermal System). The method and control values of threshold measurements have been described in detail elsewhere. ${ }^{1923}$

\section{Vibration threshold measurement}

Vibration perception threshold (VPT) was measured in all subjects on the dorsal aspect of the middle of the right second metacarpal bone and on the dorso-medial aspect of the middle of the right first metatarsal bone where the overlying subcutaneous tissue is thin. The technique, its physiological basis and normal values have been described. ${ }^{20}$ Briefly, the vibration stimulus intensity is assessed from the displacement of the skin in micrometres and not from the voltage applied to the vibrameter. The degree of displacement of skin is the physiological stimulus to the vibration-sensitive receptors. $^{20} 24$ The apparatus (Somedic AB Vibrameter type III) consists of an electromagnetic vibrator with a $13 \mathrm{~mm}$ diameter probe which vibrates at right angles to the skin. The amplitude of the skin displacement (the vibration amplitude) is measured indirectly by an accelerometer with continuous digital display. The vibrator is held against the skin with a force of $500 \pm 100 \mathrm{~g}$ by reference to a force indicator on the Vibrameter. The subject is placed in a comfortable position, the right leg is supported by pillows to prevent stimulus spread and a suprathreshold test is applied to familiarise him/her with the sensation produced. The apparatus can deliver two standardised rates of increase in stimulus intensity, slow or fast. The amplitude of vibration is increased using one of these alternatives and the subject is instructed to indicate when he/she feels the stimulus. The vibration amplitude is repeated at the alternative rate of increase of stimulus intensity. The average of three trials is taken as the VPT. In cases where there is more than $10 \%$ variation between the values, further trials are performed until 3 consecutive readings are within the $10 \%$ limit.

Vibration amplitudes in the range of $0-399.9 \mu \mathrm{m}$ at 100 $\mathrm{Hz}$ can be produced by the apparatus. The VPT determinations are made in a quiet room with a constant ambient temperature $\left(22 \pm 2^{\circ} \mathrm{C}\right)$. Skin temperature is kept at $34 \pm$ $1{ }^{\circ} \mathrm{C}$ with a thermostatically controlled heat source. On the average less than 5 minutes is required for each VPT determination. All investigations were carried out by the same person (GAJ).
PATIENTS AND CONTROL SUBJECTS

The normal values for various tests come from different control groups. Healthy control groups were drawn from among the staff and their relatives of the Institute of Neurological Sciences, Southern General Hospital, Glasgow. There were 61 control subjects for the thermal thresholds aged 35-73 $($ mean $=45 \cdot 5, \mathrm{SD}=11 \cdot 8)$ years. The control group for the EMG and NC studies contained 21 healthy subjects aged $23-69$ (mean $=46, S D=12$ ) years. The control group for the vibration threshold measurement consisted of 27 subjects aged 17-64 (mean $=46 \cdot 2, S D=11 \cdot 5$ ) years.

\section{Patients}

Twenty four patients with clinical, radiological and biochemical evidence of acromegaly attending the Department of Medicine at the Western Infirmary, Glasgow, were included in this study. Their ages ranged from 26 to 78 (mean $=48, \mathrm{SD}=15.4$ ) years. There were 14 female and 10 male patients. All the patients were informed about the nature and purpose of the study and agreed to participate. Those thought to have excessive alcohol intake or to be taking drugs likely to cause peripheral nerve dysfunction were excluded from the study. All patients had received some treatment for their acromegaly. This and other clinical details are shown in table 1 which include, where available, the hormonal status both at diagnosis and at the time of the neurophysiological studies.

All patients had been admitted to hospital for full biochemical and endocrinological evaluation within 6 months prior to the neurophysiological measurements. ${ }^{25} \mathrm{~A}$ standard $50 \mathrm{~g}$ oral glucose tolerance test was performed on each after an overnight fast. Blood samples (venous cannula) were taken at the time of glucose ingestion and at 30 minute intervals for 2 hours for blood glucose and $\mathrm{HGH}$ estimations. The areas under glucose and HGH curves during the glucose tolerance test were also measured. A "HGH day curve" from blood samples taken during one day at $800,1100,1300$, 1700 and 1900 hours, was also performed to obtain the mean circulatory HGH concentration. HGH was measured by radioimmunoassay using the 1 st international reference preparation (MRC $66 / 127 ; 1 \mathrm{mcg} / \mathrm{l}=2 \mathrm{mu} / \mathrm{l}$ ). Each patient, in addition, had a standard intravenous thyrotrophinreleasing hormone test ${ }^{26}$ during which the thyroid stimulating hormone (TSH) and $\mathrm{HGH}$ were measured at intervals of 0,20 and 60 minutes after intravenous administration of $200 \mu \mathrm{g}$ of synthetic thyrotrophin-releasing hormone. Total exchangeable body sodium was determined by the method of Davies and Robertson ${ }^{27}$ and was expressed as a percentage of that expected in a normal individual of the same body surface area and sex. Total body water was measured by tritium dilution.

\section{Results}

Table 1 shows a summary of the clinical findings. Clinical evidence of a generalised neuropathy was present in eight patients while two other patients had typical distal sensory symptoms but without objective clinical evidence on examination. Four of the eight patients had wasting of EDB muscle on both sides 
Table 1 Summary of the important clinical data in 24 patients with acromegaly at diagnosis and at the time of the neurophysiologi⿷al assessment

\begin{tabular}{|c|c|c|c|c|c|c|c|c|}
\hline \multirow[b]{2}{*}{ Case No. } & \multirow[b]{2}{*}{ Sex } & \multirow[b]{2}{*}{ Age (yr) } & \multirow[b]{2}{*}{$\begin{array}{l}\text { Clinical* } \\
\text { polyneuropathy }\end{array}$} & \multirow[b]{2}{*}{$C T S$} & \multirow[b]{2}{*}{$\begin{array}{l}\text { Clinical nerve } \\
\text { hypertrophy }\end{array}$} & \multicolumn{2}{|l|}{ At diagnosis } & \multirow{2}{*}{$\frac{\bar{\sigma}}{G \frac{\omega}{T^{\sigma}}}$} \\
\hline & & & & & & $\begin{array}{l}\text { Mean "HGH } \\
\text { day curve" }\end{array}$ & Nae & \\
\hline 1 & $\mathbf{F}$ & 68 & + & + & + & 43 & 147 & $\mathbf{N} \stackrel{\varrho}{=}$ \\
\hline 2 & $\mathrm{~F}$ & 48 & + & - & + & 67 & 126 & N \\
\hline 3 & $\mathrm{~F}$ & 38 & - & - & + & & & \\
\hline 4 & $\mathbf{M}$ & 52 & + & - & + & & & $\mathbf{N} \overline{\overline{C O}}$ \\
\hline 5 & $\mathbf{M}$ & 30 & + & + & + & & & $\mathbf{N} \stackrel{0}{+}$ \\
\hline 6 & $\mathbf{M}$ & 46 & - & - & - & 39 & 133 & No \\
\hline 7 & $\mathbf{M}$ & 66 & + & - & + & 17 & 126 & $\mathrm{Ab}$ 通 \\
\hline 8 & $\mathrm{~F}$ & 30 & - & + & + & & & \\
\hline 9 & $\mathrm{~F}$ & 68 & + & - & - & & & $\mathrm{N} \stackrel{0}{T}$ \\
\hline 10 & $\mathbf{M}$ & 26 & - & - & - & 618 & 118 & $\mathbf{N} \vec{D}$ \\
\hline 11 & $\mathbf{M}$ & 43 & - & - & - & 135 & 132 & N \\
\hline 12 & $\mathrm{~F}$ & 52 & - & - & - & 19 & 120 & N \\
\hline 13 & $\mathrm{~F}$ & 62 & - & - & - & & & \\
\hline 14 & $\mathrm{~F}$ & 29 & - & - & - & 36 & 114 & \\
\hline 15 & $\mathbf{M}$ & 30 & - & + & - & & 139 & $\mathbf{N}$ \\
\hline 16 & $\mathbf{F}$ & 56 & - & + & - & 63 & 134 & \\
\hline 17 & $\mathrm{~F}$ & 65 & - & + & - & 109 & 134 & \\
\hline 18 & $\mathbf{F}$ & 54 & - & + & - & 97 & 120 & $\mathbf{N}$ \\
\hline 19 & $\mathbf{M}$ & 65 & + & + & + & 140 & 155 & $A \mathrm{~b} \bar{z}$ \\
\hline 20 & $\mathbf{F}$ & 42 & - & - & + & 36 & 108 & \\
\hline 21 & $\mathbf{M}$ & 78 & + & + & + & 80 & 153 & \\
\hline 22 & $\mathbf{M}$ & 37 & - & + & - & 38 & 131 & $\mathbf{N}$ \\
\hline 23 & $\mathbf{F}$ & 35 & - & - & - & 29 & 115 & $\mathbf{N}$ \\
\hline 24 & $\mathbf{F}$ & 33 & - & - & - & 16 & 107 & $\mathbf{N} \infty$ \\
\hline
\end{tabular}

*All patients with $(+)$ had signs of weakness and/or wasting of small muscles of the foot and hyposensation to one or more of the following in a stocking-glove distribution: pinprick, light touch, vibration with or without symptoms (paraesthesiae, numbness, abnormal heat or cold sensation) generalised neuropathy.

Abbreviations: F: female; M: male; + : present; - : absent; N: normal; Abn: abnormal; H: hypophysectomy; I: irradiation; CTS: carpal tunnel sy Nae: total exchangeable body sodium; GTT: glucose tolerance test; HGH: human growth hormone; TRH: thyrotrophin-releasing hormone.

accompanied by weakness of toe flexion and extension and cupping of the sole of the feet while the power of ankle joint or more proximal movements were not reduced. Reflexes were diminished in all the eight patients; in one patient all reflexes were lost whereas in the remaining seven ankle jerks were lost and knee jerks were either absent (four patients) or only present on reinforcement (three patients). Clinical abnormality of reflexes in these eight patients was accompanied by abnormalities of H-reflex on electrical testing. All the eight patients had distal sensory changes in both lower limbs in the form of hyposensation to pinprick (6/8), light touch $(7 / 8)$ and vibration $(7 / 8)$ in a stocking distribution. Distal sensory symptoms including numbness, paraesthesia and abnormal heat or cold sensation were present in only five of these eight patients with objective sensory changes. In 10 patients, mostly with clinical evidence of neuropathy, the ulnar and/or the lateral popliteal nerves were considered to be enlarged clinically.

The results of the neurophysiological assessments of the control subjects and the patients with acromegaly are summarised and compared in table 2 . The statistical significance of the results was evaluated using Student's $t$ test. It is clear from table 2 that all but one (the sural SNAP latency) of the neurophysiological parameters are significantly abnormal in the patients with acromegaly compared with the normal control groups. The mean values of the upper and lower limbs thermal and vibration thresholds, the median SNAP latency, the SDML for the LPN and median nerve were all significantly higher than corresponding means for the control groups. The mean values of the FMNCV for the LPN and median nerve and the median and sural SNAP amplitude were significantly lower than those of the control group.

The figure shows the distribution and the relative frequencies of the abnormalities for the neurophysiological tests. Values above the 95th percentile were abnormal for sensory and motor conduction and vibration threshold studies while thermal threshold values in excess of the 99th percentile were considered abnormal. The SDML and/or the FMNCV for the LPN were abnormal in $50 \%$ of the patients. The sural SNAP amplitude and/or latency were abnormal in $14 \%$ of the patients with acromegaly. A smaller number of patients had abnormalities in the sensory and/or motor median nerve conduction studies (table 3).

Thermal thresholds for one or both sites were abnormal in $67 \%$ of the patients studied. The thermal threshold abnormalities were generally more marked and more frequent at the ankle $(62 \%)$ than at the wrist (42\%) (table 3). Abnormal VPT at the tarsal site 


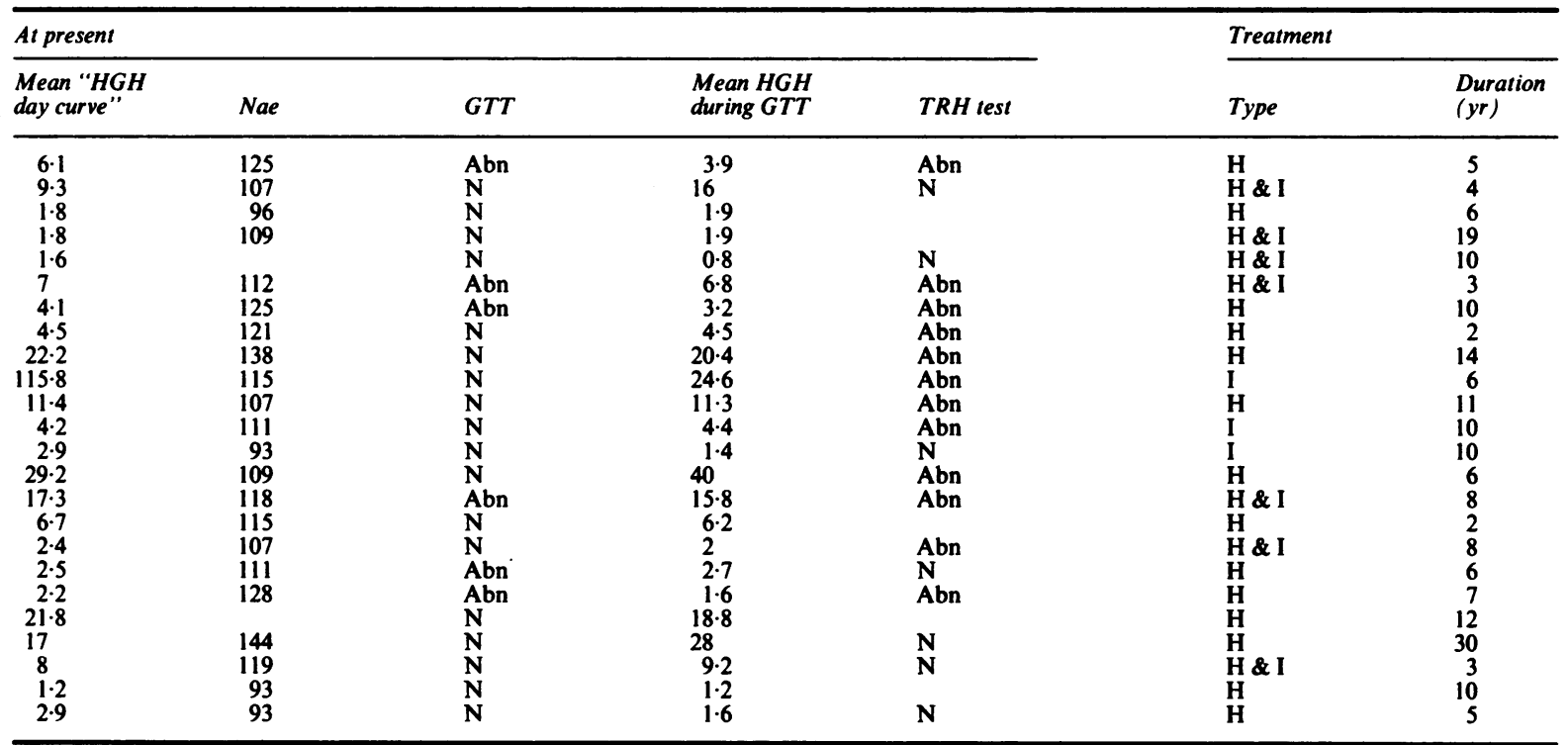

Table 2 Neurophysiological data: comparison of normal and patient groups

\begin{tabular}{|c|c|c|c|c|c|c|}
\hline Parameter & Group & $N$ & Mean & $S D$ & Units & $p$ \\
\hline $\begin{array}{l}\text { Ankle HT } \\
\text { Ankle CT } \\
\text { Wrist HT } \\
\text { Wrist CT } \\
\text { Carpal VPT } \\
\text { Tarsal VPT } \\
\text { Median SDML } \\
\text { Median FMNCV } \\
\text { Median SNAP latency } \\
\text { Median SNAP amplitude } \\
\text { SDML for LPN } \\
\text { FMNCV for LPN } \\
\text { Sural SNAP latency } \\
\text { Sural SNAP amplitude }\end{array}$ & $\begin{array}{l}\text { Normal } \\
\text { Acromegaly } \\
\text { Normal } \\
\text { Acromegaly } \\
\text { Normal } \\
\text { Acromegaly } \\
\text { Normal } \\
\text { Acromegaly } \\
\text { Normal } \\
\text { Acromegaly } \\
\text { Normal } \\
\text { Acromegaly } \\
\text { Normal } \\
\text { Acromegaly } \\
\text { Normal } \\
\text { Acromegaly } \\
\text { Normal } \\
\text { Acromegaly } \\
\text { Normal } \\
\text { Acromegaly } \\
\text { Normal } \\
\text { Acromegaly } \\
\text { Normal } \\
\text { Acromegaly } \\
\text { Normal } \\
\text { Acromegaly } \\
\text { Normal } \\
\text { Acromegaly }\end{array}$ & $\begin{array}{l}40 \\
24 \\
40 \\
24 \\
40 \\
24 \\
40 \\
24 \\
27 \\
24 \\
27 \\
24 \\
21 \\
24 \\
21 \\
24 \\
21 \\
24 \\
21 \\
24 \\
21 \\
24 \\
21 \\
24 \\
21 \\
24 \\
21 \\
24\end{array}$ & $\begin{array}{c}1 \cdot 59 \\
4 \cdot 17 \\
0 \cdot 18 \\
0.43 \\
0.23 \\
0.55 \\
0 \cdot 16 \\
0.26 \\
0.8 \\
1.21 \\
1.63 \\
4 \cdot 42 \\
3.54 \\
3.98 \\
58 \cdot 6 \\
54 \cdot 8 \\
2.92 \\
3.52 \\
17.8 \\
11.7 \\
3.59 \\
4.5 \\
50 \cdot 5 \\
45.9 \\
3.62 \\
3.53 \\
6.8 \\
4.8\end{array}$ & $\begin{array}{l}0.82 \\
2.16 \\
0.07 \\
0.28 \\
0.07 \\
0.62 \\
0.05 \\
0 \cdot 21 \\
0.41 \\
1.51 \\
0.45 \\
6 \cdot 13 \\
0.35 \\
0.77 \\
4 \cdot 8 \\
7.66 \\
0.26 \\
0.99 \\
7 \\
8 \\
0.44 \\
0.9 \\
4 \cdot 6 \\
3.4 \\
0.44 \\
0.42 \\
2 \\
2 \cdot 15\end{array}$ & $\begin{array}{l}{ }^{\circ} \mathrm{C} \\
{ }^{\circ} \mathrm{C} \\
{ }^{\circ} \mathrm{C} \\
{ }^{\circ} \mathrm{C} \\
\text { um } \\
\text { um } \\
\mathrm{ms} \\
\mathrm{m} / \mathrm{s} \\
\mathrm{ms} \\
\mathrm{uv} \\
\mathrm{ms} \\
\mathrm{m} / \mathrm{s} \\
\mathrm{ms} \\
\mathrm{uv}\end{array}$ & $\begin{array}{l}<0.001 \\
<0.001 \\
<0.02 \\
<0.03 \\
\mathrm{NS} \\
<0.05 \\
<0.02 \\
<0.05 \\
<0.01 \\
<0.01 \\
<0.001 \\
<0.001 \\
\text { NS } \\
<0.005\end{array}$ \\
\hline
\end{tabular}

Abbreviations: HT: heat threshold; CT:cold threshold; VPT: vibration perception threshold; SDML: shortest distal motor latency; FMNCV: fastest motor nerve conduction velocity; SNAP: = sensory nerve action potential; LPN: lateral popliteal nerve. 

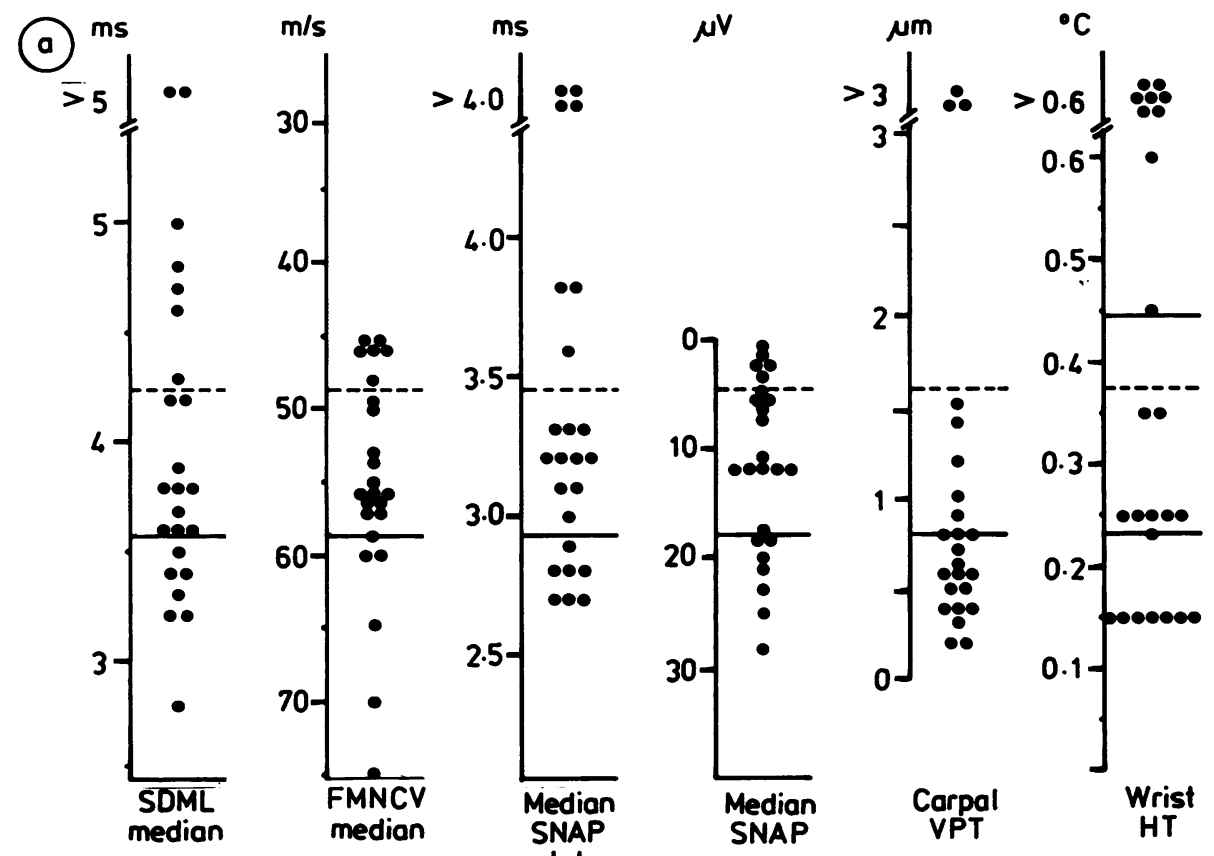

${ }^{\circ} \mathrm{C}$

(b)

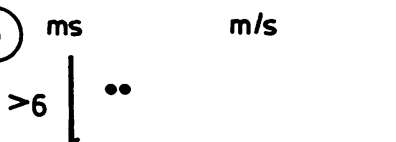

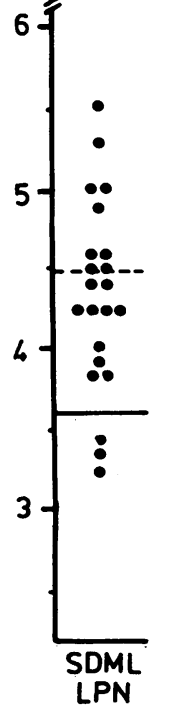

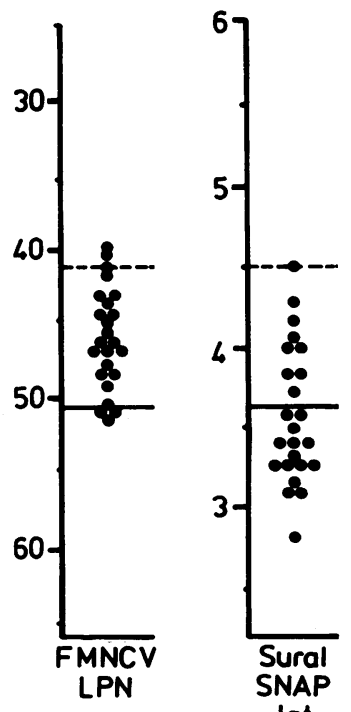

lat
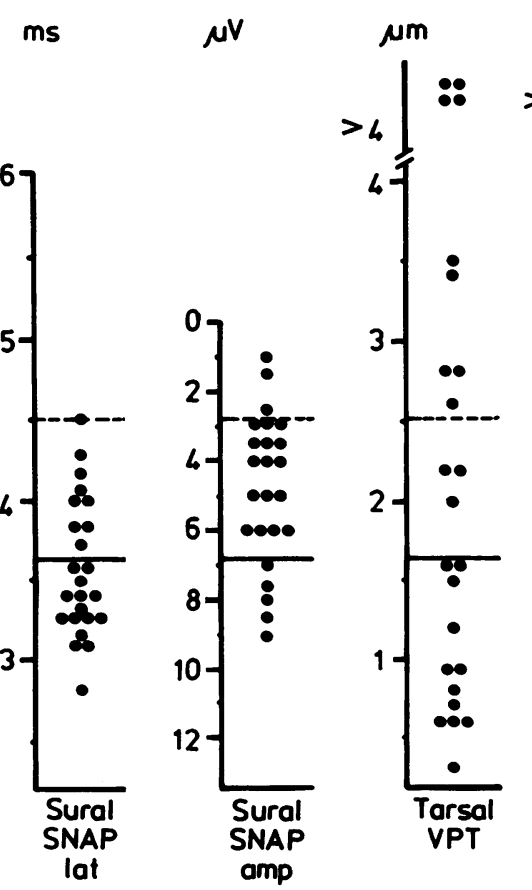

${ }^{\circ} \mathrm{C} \quad{ }^{\circ} \mathrm{C}$
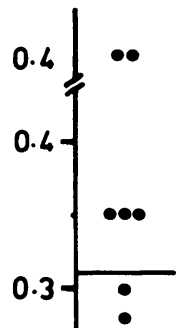

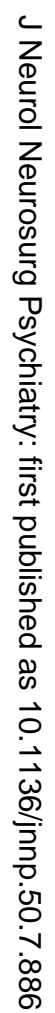

Fig The distribution of the values of the neurophysiological tests performed in 24 patients with acromegaly. A: in the upper limb; B: in the lower limb. The scales are drawn so that control means and control standard deviations coincide to render comparison easy. The axes of the median and sural SNAP amplitudes and the LPN and median FMNCVS are reversed so that abnormalities are shown as shifts in upward direction for all the parameters. HT: heat threshold; $C T$ : cold threshold; SNAP: sensory nerve action potential; SDML: shortest distal motor latency; FMNCV: fastest motor nerve conduction velocity; LPN: lateral popliteal nerve; VPT: vibration perception threshold. 
Table 3 Frequency of abnormality of neurophysiological parameters in 24 patients with acromegaly

\begin{tabular}{|c|c|c|c|}
\hline \multirow{2}{*}{$\begin{array}{l}\text { Neurophysiological } \\
\text { parameter }(s)\end{array}$} & \multirow{2}{*}{$\begin{array}{l}\text { Criteria of } \\
\text { abnormality }\end{array}$} & \multicolumn{2}{|c|}{$\begin{array}{l}\text { Patients with } \\
\text { abnormal values }\end{array}$} \\
\hline & & No. & $\%$ \\
\hline $\begin{array}{l}\text { Ankle HT } \\
\text { Ankle CT } \\
\text { Wrist HT } \\
\text { Wrist CT } \\
\text { Tarsal VPT } \\
\text { Carpal VPT } \\
\text { Median SDML } \\
\text { Median FMNCV } \\
\text { Median SNAP latency } \\
\text { Median SNAP amplitude } \\
\text { SDML for LPN } \\
\text { FMNCV for LPN } \\
\text { Sural SNAP latency } \\
\text { Sural SNAP amplitude } \\
\text { HT and/or CT at ankle } \\
\text { HT and/or CT at wrist } \\
\text { HT and/or CT at wrist }\end{array}$ & $\begin{array}{l}99 \% \text { CL } \\
99 \% \text { CL } \\
99 \% \text { CL } \\
99 \% \text { CL } \\
95 \% \text { CL } \\
95 \% \text { CL } \\
95 \% \text { CL } \\
95 \% \text { CL } \\
95 \% \text { CL } \\
95 \% \text { CL } \\
95 \% \text { CL } \\
95 \% \text { CL } \\
95 \% \text { CL } \\
95 \% \text { CL } \\
99 \% \text { CL } \\
99 \% \text { CL }\end{array}$ & $\begin{array}{r}14 \\
9 \\
9 \\
5 \\
9 \\
3 \\
7 \\
6 \\
7 \\
5 \\
11 \\
3 \\
1 \\
3 \\
15 \\
10\end{array}$ & $\begin{array}{r}58 \\
37 \\
37 \\
21 \\
37 \\
12 \\
29 \\
25 \\
29 \\
21 \\
46 \\
12 \\
4 \\
12 \\
62 \\
42\end{array}$ \\
\hline $\begin{array}{l}\text { and/or ankle } \\
\text { Carpal and/or Tarsal VPT } \\
\text { SDML and/or FMNCV }\end{array}$ & $\begin{array}{l}99 \% \mathrm{CL} \\
95 \% \mathrm{CL}\end{array}$ & $\begin{array}{r}16 \\
9\end{array}$ & $\begin{array}{l}67 \\
37\end{array}$ \\
\hline $\begin{array}{l}\text { for LPN } \\
\text { Sural SNAP latency }\end{array}$ & $95 \% \mathrm{CL}$ & 12 & 50 \\
\hline $\begin{array}{l}\text { and/or amplitude } \\
\text { Abnormal LPN and/or }\end{array}$ & $95 \% \mathrm{CL}$ & 4 & 17 \\
\hline sural NC studies & $95 \% \mathrm{CL}$ & 12 & 50 \\
\hline
\end{tabular}

Abbreviations: As in table 2. was encountered in $37 \%$ of the patients while $12 \%$ had VPT abnormality at the carpal site (table 3 ).

The diagnosis of carpal tunnel syndrome was made on both clinical and electrophysiological evidence. The clinical criteria of carpal tunnel syndrome included one or more of the following features: paraesthesiae in the distribution of the median nerve; wasting and/or weakness of the APB muscle and sensory impairment in the median nerve distribution of the hand. The electrophysiological criteria of carpal tunnel syndrome included one or more of the following abnormalities: a prolonged median nerve SDML, a prolonged median SNAP latency and a reduced median SNAP amplitude at the wrist. These criteria had to obtain in the presence of normal ulnar nerve and proximal median nerve conduction studies. Ten patients had both clinical and electrophysiological criteria of carpal tunnel syndrome $(42 \%)$. In five patients, two of whom had bilateral carpal tunnel syndrome, this was the only abnormality in their neurophysiological tests. In the remaining five of the carpal tunnel syndrome patients, there was also evidence, from one or more of the neurophysiological tests performed on the lower limbs, of a widespread subclinical dysfunction of the peripheral nerves and their end organs (table 4).

Table 4 Summary of some of the neurophysiological tests in 10 patients with acromegaly associated carpal tunnel syndrome

\begin{tabular}{|c|c|c|c|c|c|c|c|c|c|c|c|c|c|}
\hline \multirow{3}{*}{$\begin{array}{l}\text { Patient } \\
\text { No. }\end{array}$} & \multicolumn{4}{|c|}{ Median nerve } & \multirow{2}{*}{\multicolumn{2}{|c|}{$\begin{array}{l}\text { Sural nerve } \\
\text { SNAP }\end{array}$}} & \multirow{3}{*}{$\begin{array}{l}L P N \\
F M N C V\end{array}$} & \multicolumn{6}{|c|}{ Thermal thresholds } \\
\hline & \multicolumn{2}{|l|}{ Motor } & \multicolumn{2}{|c|}{$S N A P$} & & & & \multicolumn{2}{|c|}{ Wrist } & \multicolumn{2}{|c|}{ Ankle } & \multicolumn{2}{|l|}{$V P T$} \\
\hline & $S D M L$ & $F M N C V$ & Lat & $A m p$ & Lat & $A m p$ & & $H T$ & $C T$ & $H T$ & $C T$ & Carpal & Tarsal \\
\hline $\begin{array}{r}15 \\
16 \\
17 \\
18 \\
22 \\
1 \\
7 \\
9 \\
19 \\
21\end{array}$ & $\begin{array}{l}4 \cdot 7 \\
4 \cdot 3 \\
5 \\
4 \cdot 8 \\
3 \cdot 6 \\
6 \\
4 \cdot 2 \\
4 \cdot 6 \\
3 \cdot 8 \\
5 \cdot 4\end{array}$ & $\begin{array}{l}50 \\
49 \cdot 5 \\
53 \cdot 5 \\
49 \\
50 \\
46 \\
54 \cdot 3 \\
60 \\
55 \\
46\end{array}$ & $\begin{array}{l}4 \cdot 5 \\
3 \cdot 2 \\
3 \cdot 8 \\
6 \cdot 5 \\
3.6 \\
5 \cdot 4 \\
4 \cdot 5 \\
3 \cdot 3 \\
3 \cdot 8 \\
5 \cdot 5\end{array}$ & $\begin{array}{l}5 \\
12 \\
5 \\
0 \cdot 5 \\
12 \\
3 \cdot 5 \\
3 \\
7 \\
4 \\
2\end{array}$ & $\begin{array}{l}4 \cdot 5 \\
4 \\
3 \cdot 3 \\
3 \cdot 4 \\
3 \cdot 8 \\
4 \cdot 3 \\
3 \cdot 6 \\
3 \cdot 3 \\
3 \cdot 3 \\
4 \cdot 0\end{array}$ & $\begin{array}{l}3 \\
5 \\
6 \\
5 \\
6 \\
4 \\
3 \cdot 5 \\
3 \\
3 \cdot 5 \\
4\end{array}$ & $\begin{array}{l}44 \cdot 2 \\
45 \\
46 \\
44 \\
50 \\
43 \cdot 4 \\
41 \cdot 7 \\
46 \cdot 4 \\
43 \\
46\end{array}$ & $\begin{array}{l}0.15 \\
0.15 \\
0.15 \\
0.15 \\
0.25 \\
0.35 \\
1.45 \\
0.65 \\
1.45 \\
0.35\end{array}$ & $\begin{array}{l}0.15 \\
0.15 \\
0.15 \\
0.15 \\
0.15 \\
0.25 \\
0.95 \\
0.28 \\
0.35 \\
0.25\end{array}$ & $\begin{array}{l}2.85 \\
2.95 \\
1.35 \\
3.45 \\
3.15 \\
5.65 \\
6.75 \\
7 \cdot 35 \\
5 \cdot 25 \\
4.20\end{array}$ & $\begin{array}{l}0.25 \\
0.75 \\
0.25 \\
0.35 \\
0.25 \\
0.35 \\
1.15 \\
0.45 \\
0.65 \\
0.75\end{array}$ & $\begin{array}{l}0.4 \\
0.6 \\
0.2 \\
0.8 \\
0.6 \\
5.7 \\
5.6 \\
0.7 \\
0.8 \\
0.9\end{array}$ & $\begin{array}{c}0.6 \\
2.2 \\
0.9 \\
1.5 \\
1.6 \\
45 \\
\frac{10.6}{3.5} \\
\frac{5.6}{2.6}\end{array}$ \\
\hline
\end{tabular}

Abbreviations: As for table 2. Abnormal values for VPT and thermal thresholds are underlined.

Table 5 Correlations between total exchangeable body sodium and the neurophysiological parameters in 22 patients with acromegaly

\begin{tabular}{|c|c|c|c|c|}
\hline \multirow[b]{2}{*}{ Neurophysiological parameter } & \multicolumn{2}{|c|}{ At the time of diagnosis of acromegaly } & \multicolumn{2}{|l|}{ At present } \\
\hline & $r$ & $p$ & $r$ & $p$ \\
\hline
\end{tabular}

Abbreviations: As in table 2. 
There was no significant correlation between the neurophysiological parameters and values of fasting blood sugar, two hour post-prandial glucose, the area under glucose curve during GTT, human growth hormone (HGH), mean HGH during the glucose tolerance test (GTT), the area under HGH curve during GTT, mean "HGH day curve" and TSH levels at 20 and 60 minute intervals during the thyrotrophinreleasing hormone test. The neurophysiological parameters also did not correlate with these endocrinological data performed at the time of the diagnosis of acromegaly before treatment. Significant correlation, however, was found between most of these neurophysiological tests and the total exchangeable body sodium (table 5 ). No correlation was found between duration of diagnosis of acromegaly and the neurophysiological parameters. It is accepted, however, that the lack of correlation may be due to the difficulty of estimation of the actual duration of this disorder.

\section{Discussion}

The results obtained in this study using a number of independent neurophysiological techniques, indicate the presence of a generalised impairment of peripheral motor and sensory nerves in acromegaly. Onethird of the patients had clinical and two-thirds had neurophysiological evidence of a generalised neuropathy. Local nerve entrapments were present in $\mathbf{1 0}$ of the 24 patients.

Several isolated cases of "hypertrophic" neuropathy have been described in association with acromegaly. ${ }^{11-13}$ In a small series of patients with acromegaly, $45 \%$ were found to have some enlargement of peripheral nerves clinically. ${ }^{15}$ Sural nerve histology in some of these patients showed endoneurial and subperineurial tissue hypertrophy. ${ }^{11214}$ These findings were supported by Low and associates ${ }^{15}$ who also demonstrated an increase in the fascicular areas of the sural nerves. Ten of our patients $(42 \%)$ had clinical evidence of enlargement of peripheral nerves on examination.

The sural sensory action potential (SNAP), when measured to the peak, gives information in its latency about the modal peak of the conduction velocity of the large myelinated nerve fibre velocity population. ${ }^{28}$ The amplitude gives information about the number of nerve fibres stimulated with a wide variety of velocities. ${ }^{28}$ This test was abnormal in $14 \%$ of the patients (table 3). Abnormal tarsal vibration perception threshold was found in $37 \%$ of the patients, an indication of involvement of the large fibre afferent nerve pathway. ${ }^{20}$ The abnormality of VPT was less severe and less frequent at the carpal site compared with the more distal tarsal position. As the method measures VPT from the displacement of skin rather than the voltage applied, ${ }^{20}$ local changes of skin and subcutaneous tissue does not influence VPT measurements.

Thermal thresholds are an indication of function in the small nerve fibre afferent pathway. ${ }^{29}$ In the acromegalic patients abnormalities of thermal thresholds were more severe at the ankle $(67 \%)$ than at the wrist $(42 \%)$. The increase in thermal threshold values in these patients is unlikely to be due to soft tissue hypertrophy as the thermode is calibrated before each threshold measurement so that the rate of temperature change is independent on skin thickness. ${ }^{19}$ Sural nerve histological studies in acromegaly have demonstrated a decrease in the density of unmyelinated and myelinated fibres with signs of segmental demyelination and remyelination. ${ }^{15}$

Our results suggest involvement of both small and large fibre pathways. In addition, the combination of all the neurophysiological and perceptual tests with the greater frequency of thermal and vibration sense abnormalities distally is similar to the pattern of involvement in many metabolic and toxic peripheral neuropathies where the most severe abnormality occurs in the longest nerve fibre.

No significant correlation was found between the values of the neurophysiological tests and the associated glucose intolerance, the level of $\mathrm{HGH}$ in plasma, the mean "HGH day curve", the mean HGH during the glucose tolerance test and the 20 and 60 minute TSH hormone levels during the thyrotrophinreleasing hormone test. This is in agreement with Low et $a l^{15}$ and Pickett $e t a l^{8}$ who fcund no correlation of the peripheral neuropathy with HGH levels and the associated diabetes mellitus in acromegaly. Total exchangeable body sodium is increased in acromegaly 253031 and may reflect disease activity since it correlates with $\mathrm{HGH}$ levels ${ }^{31}$ and with the duration of the disease process ${ }^{25}$ and also falls following successful treatment. ${ }^{25}$ Most of the neurophysiological parameters showed a significant correlation with total exchangeable body sodium; the higher the total exchangeable body sodium, the more abnormal were the neurophysiological tests (table 5). This would reflect a generalised neuropathy which increases in severity with disease activity.

The independence of the neurophysiological data from the glucose intolerance and the pituitary thyroid dysfunction suggests that the neuropathy is not aetiologically similar to that of diabetes mellitus or hypothyroidism. In view of the known correlation between total exchangeable body sodium and $\mathrm{HGH}^{25}{ }^{31}$ the lack of an association between HGH and the neurophysiological data is difficult to explain but may be due to a different rate of change in the two variables following treatment in this heterogenous 
group of treated acromegalic patients. However, the generalised peripheral neuropathy seems likely to be due to an effect mediated through excessive human growth hormone levels the exact mechanism, remains to be determined.

Unilateral or bilateral carpal tunnel syndrome was present in 10 of our 24 patients. This is in agreement with other published series. ${ }^{89}$ The results show that in $50 \%$ of patients with acromegaly associated carpal tunnel syndrome, there is an underlying generalised peripheral neuropathy but equally there are $50 \%$ who develop the entrapment neuropathy independent of any generalised process.

\section{Conclusion}

Generalised peripheral nerve dysfunction is common in patients with acromegaly. The peripheral nerve abnormality does not correlate with the associated diabetes mellitus, the circulating levels of growth hormone, and the pituitary thyroid function. A significant correlation exists between the presence and severity of the peripheral neuropathy and total exchangeable body sodium. Compression neuropathies either as part of the generalised dysfunction, or independent of it, occur frequently. The exact mechanism of this peripheral nerve dysfunction in acromegaly remains to be determined.

We thank Professor J A Simpson, Drs J P Ballantyne, ID Melville, I Bone, A M Thomas and S Hansen for their helpful comments about the manuscript. We thank Mrs M McColl for secretarial assistance.

The Somedic Vibrameter was supplied by Pfizer Limited.

Dr G A Jamal was supported during the later part of the study by Pfizer Limited.

\section{References}

1 Woltman HW. Neuritis associated with acromegaly. Arch Neurol Psychiat 1941;45:680-2.

2 Schiller F, Kolb FO. Carpal tunnel syndrome in acromegaly. Neurology 1954;4:271-82.

3 Kellgren JH, Ball J, Tutton GK. The articular and other limb changes in acromegaly; a clinical and pathological study of 25 cases. $Q J$ Med 1952;21:405-24.

4 Johnston AW. Acroparaesthesiaes and acromegaly. Br Med J 1960;1:1616-8.

5 Skanse B. Carpal tunnel syndrome in myxedema and acromegaly. Acta Chir Scand 1961;121:476-80.

6 Brain WR, Wright AD, Wilkinson M. Spontaneous compression of both median nerves in the carpal tunnel. Lancet 1947;1:277-82.

7 Sullivan CR, Jones DR, Bahn RC, Randall RV. Clinics on endocrine and metabolic diseases. 9. Biopsy of the costochondral junction in acromegaly. Proc Mayo Clin 1963;38:81-6.
8 Pickett JBE, Layzer RB, Levin SR, Schneider V, Campbell MJ, Sumner AJ. Neuromuscular complications of acromegaly. Neurology 1975;25:638-45.

9 O'Duffy JD, Randal RV, MacGarthy CS. Median neuropathy (carpal tunnel syndrome) in acromegaly. Ann Int Med 1973;78:379-83.

10 Humberd CD. Giantism. Report of a case. JAMA 1937;108:544-6.

11 Stewart BM. The hypertrophic neuropathy of acromegaly: a rare neuropathy associated with acromegaly. Arch Neurol 1966;14:107-10.

12 Dinn JJ. Schwann cell dysfunction in acromegaly. J Clin Endocr Metab 1970;31:140-3.

13 Lewis DD. Neuromuscular involvement in pituitary gigantism. Br Med J 1972;2:499-500.

14 Sandbank U, Bornstein B, Najenson T. Acidophilic adenoma of the pituitary with polyneuropathy. $J$ Neurol Neurosurg Psychiatry 1974;37:324-9.

15 Low PA, McLeod JG, Turtle JR, Donnelly P, Wright RG. Peripheral neuropathy in acromegaly. Brain 1974;97:139-52.

16 Lucey C. Neuromuscular involvement in pituitary gigantism. Br Med J 1972;3:40-50.

17 Khaleeli AA, Levy RD, Edwards RHT, McPhail G, Mills KR, Round JM, Betteridge DJ. The neuromuscular features of acromegaly: a clinical and pathological study. J Neurol Neurosurg Psychiatry i984;47:1009-15.

18 McLeod JG, Pollard JD. Neuropathies in systemic diseases: hidden and overt. In: Asbury AK, Gilliatt RW, eds. Peripheral Nerve Disorders. London: Butterworth, 1984:92-125.

19 Jamal GA, Hansen S, Weir AI, Ballantyne JP. An improved automated method for the measurement of thermal thresholds. 1. Normal subjects. J Neurol Neurosurg Psychiatry 1985;48:354-60.

20 Goldberg JM, Lindblom U. Standardised method of determining vibratory perception thresholds for diagnosis and screening in neurological investigation. $J$ Neurol Neurosurg Psychiatry 1979;42:793-803.

21 Lenman JAR, Ritchie AE. Clinical Electromyography. Third edition. London: Pitman, 1983.

22 Gilliatt RW, Sears TA. Sensory nerve action potentials in patients with peripheral nerve lesions. $J$ Neurol Neurosurg Psychiatry 1958;21:109-18.

23 Wetherhill GB, Chen H, Vasudeva RB. Sequential estimation of quantal response curves. A new method of estimation. Biometrika 1966;543:439-54.

24 Lindblom U, Lund L. The discharge from vibrationsensitive receptors in the monkey foot. Exp Neurol 1966;15:401-17.

25 Davies DL, Beastall GH, Connell JMC, Fraser R, McCruden D, Teasdale GM. Body composition, blood pressure and the renin-angiotensin system in acromegaly before and after treatment. $J$ Hypertension (in press) (1987).

26 Ormston BJ, Garry R, Cryer RJ, Besser GM, Hall R. Thyrotrophin-releasing hormone as a thyroidfunction test. Lancet 1971;2:10-4.

27 Davies DL, Robertson JWK. Simultaneous measurement of total exchangeable potassium and sodium using ${ }^{43} \mathrm{~K}$ and ${ }^{24} \mathrm{~N}$. Metabolism 1973;22:133-7. 
28 Buchthal F, Rosenfalck A, Behse F. Sensory potentials of normal and diseased nerves. In: Dyck PJ, Thomas PK, Lambert EH, Bunge R, eds. Peripheral Neuropathy. London: WB Saunders, 1984;1:981-1015.

29 Jamal GA, Weir AI, Hansen S, Ballantyne JP. An improved automated method for the measurement of thermal thresholds. 2. Patients with peripheral neuropathy. J Neurol Neurosurg Psychiatry 1985;48:
361-6.

30 Ikkos D, Luft R, Sjogren B. Body water and sodium in patients with acromegaly. J Clin Invest 1954;33: 989-94.

31 Snow MH, Piercy DA, Robson V, Wilkinson R. An investigation into the pathogenesis of hypertension in acromegaly. Clin Sci 1977;53:87-91. 